\title{
Operating room redesign: building safety through a culture of teamwork
}

\author{
Aileen R Killen
}

Consensus is developing among experts in the field of perioperative safety about the need to redesign operating rooms (ORs) to improve patients' safety. Research in patient safety in the OR has confirmed that fewer mistakes and fewer near misses arise when surgeons work in a familiar room (Christian CK et al. [2006] Surgery 139: 159-173). For years, I thought surgeons who insisted on operating in a particular room were just being stubborn-little did I know!

The guiding principles for OR design are simple: standardize the location of the head of the table and the handedness of the room, have enough space for staff to move around and for equipment, keep the focus on the one square foot of the patient that is of interest, ensure that all staff have a line of sight to the patient at all times, use technology to help workflow, and do not automate broken workflows. By taking these steps, hospitals can certainly help reduce error rates. Commitment to improving safety in the OR, however, should not stop here. Something else much more difficult, but perhaps even more important, is building a culture that promotes teamwork and communication.

Complex surgical procedures, such as robotically assisted laparoscopic radical prostatectomy, often require six or more people working together in the OR. Although this group is usually referred to as a team, the members do not necessarily function in this manner. For example, surveys of OR staff show that surgeons report teamwork to be much better than do nurses and anesthesiologists on the same team (Mackary MA et al. [2006] J Am Coll Surg 202: 746-752).

How your operating team is doing can be assessed without an extensive survey. The
Something

... even more

important

is building a

culture that

promotes

teamwork and

communication

AR Killen is Director of the Patient Safety

Program at Memorial Sloan-Kettering

Cancer Center, New

York, NY, USA.

Competing interests

The author declared no

competing interests.

www.nature.com/clinicalpractice doi:10.1038/ncpuro1097 following basic screening questions will help to clarify the matter: do you know the first and last names of the staff who worked with you on your last case; do you ask the charge nurse "Who is in my room today?" or do you ask "Who is on my team today?"; are all staff encouraged to speak up when something looks or feels out of the ordinary?

Working as a team requires knowledge and skills distinct from technical surgical skills. Acquiring teamwork skills demands as much practice as does learning a new surgical procedure, but they are rarely directly taught. Effective teams require core elements of coordination, cooperation, awareness and communication.

Situational awareness is a shared and accurate understanding of what is going on and what is likely to happen next. This allows a team to act correctly when things proceed as planned, and react appropriately if they do not. Formal ways to improve situational awareness include the use of briefings, debriefings and checklists.

Such ritualistic behaviors are important adjuncts to better communication. Improved communication starts, however, with the basic skills of talking with and listening to people in varying disciplines and with different responsibilities. All members of the team should be clear and precise in asking for what they need, encourage open and honest discussion, and be courteous and respectful in their replies. As simple as this sounds, it requires practice. Designing and implementing a new culture is one of the biggest challenges we face in health care, but creating an environment of teamwork and communication in the OR is essential if we are truly committed to improving perioperative safety. 